\title{
Typological Peculiarities of the Styles of Political Thinking
}

\section{Tetyana Traverse}

\author{
Department of Social Psychology, Faculty of Psychology, Kyiv National Taras Shevchenko University
}

Email: Traversay@ukr.net

\section{Doi:10.5901/mjss.2015.v6n1s2p84}

\begin{abstract}
Political thinking style in all normative cases is characterized by the integrity of its systemic and strategic organization. At that it is a totality of individual and psychological characteristics of actor which is preconditioned by his political activity and at the same time differentiates his political activity and thinking from other actors' activity and thinking. In the systemic and strategic concept of political thinking which we have developed, the conceptual issues are the theses that its peculiarities are subjectness, practicality, nationality and creativity. The subject of political thinking functions according to the principle of polyphony, that is an important problem may be manifested heterochronically and the nature of its existence may be heterogeneous in different and/or all spheres of human life - religion, economics, politics etc. Meanings and senses are recorded in nationality. Practicality reflects actor's ability to be the political activity subject. Creativity in politics is related to the fact that politics is an activity with risks, lack of certainty etc. The tactics were manifested systemically, which was reflected in strategic tendencies of thinking, in particular mixed (universal) strategy. In its turn, in this mixed strategy there dominated the acts of combination, reconstruction and analogization, that is construction and transformation were carried out by means of rebuilding, acting by contrast (contrary to the specified situation) as to the situation structure and functions (which is reflected in the tactics of orientation towards structure and functions).
\end{abstract}

Keywords: political thinking, polyphony, political task

\section{Introduction}

Speaking of the common features of many interpretations of the notions «intellectual activity style», «cognitive style» the researchers think that «style is an instrumental characteristic of perceptive and intellectual activity of a human being; it is persistent in time and in different situations; style reflects qualitative peculiarity of mental activity» (Tolochek V. 1998, P. 163). Political thinking style in all normative cases is characterized by the integrity of its systemic and strategic organization. At that it is a totality of individual and psychological characteristics of actor which is preconditioned by his political activity and at the same time differentiates his political activity and thinking from other actors' activity and thinking.

In our research the concept of style integrates cognitive, operational and individual and personal components and is manifested in situationally (tactics) and personally (strategies) preconditioned mental acts within the limits of subjectness, practicality, notionality and creativity of political thinking.

In the systemic and strategic concept of political thinking which we have developed, the conceptual issues are the theses that its peculiarities are subjectness, practicality, notionality and creativity. The subject of political thinking functions according to the principle of polyphony, that is an important problem may be manifested heterochronically and the nature of its existence may be heterogeneous in different and/or all spheres of human life - religion, economics, politics etc. Meanings and senses are recorded in notionality. Practicality reflects actor's ability to be the political activity subject. Creativity in politics is related to the fact that politics is an activity with risks, lack of certainty etc. (T. Traverse).

The tasks theory development created preconditions for the effective use of systemic approach in the political thinking studies. Its essence is that in any situation which can be studied it is possible to single out systems which represent tasks as well as systems which provide for solving of these tasks. Specified are qualitative and quantitative characteristics of these tasks as well as methods and ways of solving them. Tasks are viewed as a special type of systems (G. Ball, G.Bruner, Y.Kozeletskiy etc.). A task is a component of activity, reflecting its goal-oriented continuity which is provided by the subject via constant transformation of the general aim into specific tactical aims. The latter consider topical changes of activity and possibilities of a person (D. N. Zavalyshyna, B. F. Lomov B F. etc.).

Based on methodological positions of the tasks theory we call "political task" a task which is involved in real political activity; it necessarily contains certain novelty, it is always a problem, which predetermines actualization and the 
process of mental acts; it potentially determines the search process direction although does not guarantee a correct and complete result. It is not a kind of task on political topic which is set "from outside" but a task subjectively formulated by actor and taken from his real political life. That is, it is first of all a practical task (to win the elections; to implement certain programs; to provide the program support etc.) A political task is an instance of social task, since politics is one of the spheres of the society existence. In this context the notions "task with political subject matter" and "political task" are synonyms.

We relate psychological matter and peculiarities of political tasks to the principal types of intellectual political activity. What is meant here are the system-creative types of political activity and the types of political tasks which are preconditioned by them - for analogizing (hereinafter will be referred to as - A), forecasting (F), decision making (DM) and managing $(\mathrm{M})$.

The aim of the article is to present the results of the research of actor's political thinking styles which are preconditioned by the type of task to be solved.

\section{Basic Material Presentation}

In the research there participated 200 persons which formed several groups (50 persons in each), among which there is a group of deputies from different district councils and city councils of Ukraine. The rest of the groups were formed by the students who are in a certain way involved in political activity, namely: a) those who prepare themselves for working in politics (who study political science); b) students who study neither political science nor liberal arts (those majoring in mechanical science, mathematics); c) students majoring in psychology, religious studies, philosophy; d) among the students' groups there was a group of students who participated in the political events at Maidan in autumn 2013 - winter 2014.

The research was carried out by means of the method of observation, conversation, which in the future gave reasons for developing of the author's "political thinking observation map".

All tasks to be solved had different significance for each of the respondents' groups. We consider significant such a task which was personally important, valuable for an actor, corresponded to his abilities, which was accompanied by positive emotions, and the respondents mostly demonstrated the best results when solving such a task. It may be related to the type of intellectual political activity and the prevailing type of activity demonstrated by the respondents daily : a) politicians - solving of social problems by means of politics; б) students - study activity, in particular for those who study political science the politics subject is most relevant and therefore political tasks are more understandable and acceptable; в) for students majoring in different subjects (mechanical science, mathematics, psychology, religious studies, philosophy, economics) - politics was the practice of expressing their will as citizens, and the tasks were of personal importance.

That is, in the case of politicians political thinking existed as specialists' professional thinking; in the case of students who study political science - as forming of the future professional political thinking (although in documents, f.ex. in education and qualification characteristics, we have not found such a term as "(forming of) professional political thinking"); other groups - non-professional everyday political thinking of an active participant of political events. It is this fact that we consider to be system-creative with respect to style, since what is meant are different types of political thinking - professional, potentially professional, non-professional (or everyday). According to V.O. Tolochek it is determined by objective requirements of activity (Tolochek V.A., 1992), in particular political tasks.

General peculiarities in solving of political tasks have been found.

There has also been revealed different sequence of task types with respect to significance and successfulness of their solving by the respondents. For politicians the task significance ranking looks like following: DM, M, A, F; for students who study political science - A, F, DM, Y; for Maidan participants - F,DM, M, A; for students who study mathematics - A, DM, M, F; for future psychologists and specialists in religious studies - A, F, M, DM. The first tasks in the ranking are typical for the corresponding group of respondents. The last ones are not typical, sometimes in the process of solving them the style peculiarities of political thinking were lost (sometimes the subject was lost and political thinking turned into social, economic, philosophic thinking), the solution was less successful, the solution stages were not quite coherent, the whole search process was irregularly dynamic.

Typological style peculiarities of political thinking in different groups were interesting. In particular, politicians found inconsistencies in the task texts, especially in significant tasks. Such result confirms the idea of D. Veymer, E. Vayning as to matching of politics and government, since DM and $M$ tasks are significant for them while $A$ and $F$ tasks are comparatively poorly solvable. As a last resort there may be a paradox when politicians strive to organize social and political space and make decisions in the case of the lack of development of abilities to make political analysis and 
forecasting. The corresponding tasks were evaluated by them as partial or training tasks. In the Maidan participants group the tasks significance ranking can be explained by age peculiarities of young actors as well as social and political peculiarities of their participation in the political mass events.

The main aims of the search process for politicians and Maidan participants was " power"; for students who study political science - "knowledge" and " self-actualization", for psychologists - «knowledge». It is indirectly confirmed by the above-mentioned hypothesis as to the type of political thinking in different groups of participants.

Since DM and $\mathrm{M}$ tasks were significant for politicians, we consider them to be the type of tasks which determine professional political thinking. The present theoretical generalizations, succession, coherence of thinking, formulating of conclusions, putting of knowledge in other conditions - this all contradicts with the statement of the researchers (D. Olshanskiy etc.) that political thinking is alogical. Intellectual reflection, presence of ratiocinations, preliminary conclusions is also peculiar.

Preparatory, planning and operative (implementation, evaluation and verification) actions were uniformly interrelated, that is the search process existed as an integral system. At each stage these actions were determined both by general and specific features, which is preconditioned by the structure and peculiarities of their political thinking. Operations which are «envisaged by the actions plan» are considered by us, as well as by V. O. Molyako, to be such operations that «determine the strategy of solving of the whole task» (V. O. Molyako, P. 101). Mental acts (operations), thanks to which a politician fulfilled the task requirements, were conditioned by functional and structural transformations: a) recombination methods; б) by contrast; в) universal (mixed). That is their political thinking is characterized by the uniform distribution of combinatory, reconstructing and universal actions. These «operations are perforating, which determine the new task solution» (V. O. Molyako, P. 101). At the same time no interrelations between the task type and strategy type have been revealed. However, as compared to other groups, the politicians had evidently intense and colorful manifestation of strategies, which was reflected in the offered relevant task solutions number.

In the process of the task setting there were both clear and unclear plans; in most cases actor carried out actions as to decision making concerning its quality. Politicians differentiate and comprehend «knowledge about lack of knowledge» and «knowledge about knowledge» and use operative knowledge. They clearly identify the task subjectness, singling out the meanings of an activity object. Thus they solve not a one-dimensional task, but a synthetic-political one which considers a system of necessary and sufficient aspects for its solution, which is based on "procedural knowledge" and "preliminary experience".

Interesting was the neglecting of normative meanings (ideal norms) and even standard norms, although it is a must to adhere to them in political activity. That is, politicians are ready to make the so-called extraordinary steps as to «the possible in thinking» (K. Popper's term). Therefore, the existing norms in the society are not always the determinative regulators of their political activity. Moreover, understanding and orienting in "under-certainties" in the normative field gives reasons for drawing on «politics legitimization mechanisms, which are of historical nature and are determined by qualitative parameters of the society» (Y. A. Levenets).

The forms of implementation of politics, the mechanisms of legitimization, according to $Y$. A. Levenets, «create cognitive and normative models of political reality ... regulate and structure politics, drawing on the identified interests and values. The norms on politics are the center of human interests and values, which are constantly in the field of interpretations. Since it is impossible to record in the norms the life practices in all their complicacy and variations, interpretations create a lot of reflected or contorted derivatives. Action in politics, being based on the norm, constantly tries to go beyond its limits and creates non-normativity» [5, p. 568]. The presence and orientation of creativity in politics (constructive and destructive) is related to this. One of regulatory mechanisms in the non-normative sphere is actor's political culture, which preconditions the development level and basic features of his political activity.

It creates plenty of problems, in particular, transformations: a) in the structure and peculiarities of political thinking (considering it more broadly - intellectual activity) when a person switches over from social sphere to political sphere and vice versa. In its turn it is related to the problems of possibilities and limits - society politicization, political elites circulation etc.; б) the dynamics of formation of individual and personal traits and features of a politician; B) general human values, their interrelation and co-existence in the political and social dimensions etc. However such result may be correlated with the point of view on politics as an activity which appears under the conditions when social regulators (laws, norms, rules etc.) are not enough for solving of essential problems of the society.

In all tasks mental acts created certain blocks (tactics) thanks to which the search process was organized. Most typical for politicians were synthetic tactics (that is, such tactics which contain dichotomy and are relatively balanced): a) concentration on the familiar $(0,458)$ and least familiar part of the task specification $(0,507) ; b)$ interrelation of the orientations towards meanings and senses; $c$ ) orientation towards subjects which are to participate $(0,425)$ and towards the situation implementation conditions; d) specification (differentiation) and integration (generalization); f) orientation 
towards the structure and the functions; $g$ ) orientation towards the result (that is activity is performed as work) and the process (sensitivity to side effects). Also, such tactics as interpretation, exaggeration, reduction as turning the complex into the simple - which testified that the informational basis of the politician's activity was formed $(0,453)$ etc.

The tactics were manifested systemically, which was reflected in strategic tendencies of thinking, in particular mixed (universal) strategy. In its turn, in this mixed strategy there dominated the acts of combination, reconstruction and analogization, that is construction and transformation were carried out by means of re-building, acting by contrast (contrary to the specified situation) as to the situation structure and functions (which is reflected in the tactics of orientation towards structure and functions).

A feature of politicians' political thinking is the presence in their base of «key elements», which turned out to be sensitive to certain material units; preconditioned the change in the available notion structures, determining the nature and orientation of actualization of the available knowledge and gaining of new knowledge. The politicians' majority demonstrated the knowledge working "here and now" when the whole preparatory stage of decision making was structured, strategically preconditioned, partially comprehended («...there is no need to think a lot, we are three in our team ... main tasks are ..., only two of them can be solved in practice, thanks to ...»). Such professional representation of the political task subject matter is the basic principles which reveal the peculiarities of interaction of the objects of political contexts.

Potential (non-formed) political thinking of students who study political science is the closest to professional political thinking. Firstly, clear subjectness is typical for such thinking (the same as in the case of politicians' thinking). There is intellectual readiness to solving of all experimental tasks; specification and request of the needed information. Personal experience turned out to be uniformly actualized, as well as subjective system of meanings which peak in DM, M tasks $(0,775)$.

At the same time, unlike in professional political thinking, in potentially professional political thinking ideal norms are determinative $(0,865)$, they are best manifested in significant tasks. Thus there are conscious attempts to adhere to standard norms of "peaceful, democratic resistance", "demonstration of respectful attitude to others" $(0,436)$.

Preparatory actions first appeared only in DM, M tasks. Planning actions $(0,343)$ and evaluation actions are uniformly expressed in all tasks $(0,420)$. However the extent of implementation actions is higher in significant tasks $(0,764)$. Verification actions are not intense $(0,233)$ but uniformly present in all tasks. Typical is the formulation of results, however the latter were stereotypically and ideally preconditioned which led to incorrect understanding of the task situation in general. Students tried to place the theoretical social and politic knowledge in other (practical) conditions $(0,351)$. They used the knowledge from other types of activity (study, civic etc.).

However almost no synthetic tactics were revealed. Instead there have been found out separate typical tactics: orientations towards the structure; the functions of the task situation; orientation towards the meanings (in $A, F, M$ tasks). It may be related to the interpretation of tasks as study tasks, which is evidenced by the motives "to obtain knowledge" $(0,354)$, «to self-actualize» $(0,578)$; towards the task implementation in the specific "field" conditions $(0,457)$; orientation towards meanings in DM task which is connected with prevailing of beliefs $(0,734)$. Beliefs and related stereotypes peaked $(0,854)$; the tactics of poly-logic, orientation towards dialogue, which is conditioned by the "democratic character" of their political (liberal) position; orientation towards the subjects who participate in political events (DM, M tasks); orientation towards the task structure (in A, M tasks). In general there repeats the tendency of orientation in the task space of a group of deputies where the tactics of orientation towards structures is typical for M tasks; functional - for DM tasks; structural and functional - for F tasks. Among the synthetic ones typical is the tactics of interrelation of meanings and senses in significant tasks.

Systemic display of tactics was reflected in strategic tendencies of thinking which have the following ranking: analogization $(0,647)$, combination $(0,465)$, random actions $(0,385)$, reconstruction $(0,214)$, universal $(0,036)$. That is, construction and transformation of the task space occurred by being transferred from other situations; reconstruction; random substitutions; actions by contrast as to the situation structure and functions (which is reflected in the tactics of orientation towards the structure and functions).

Typical everyday political thinking is in the brightest way represented $0 \mathrm{n}$ the group of students - Maidan participants. For them typical was prevailing actualization of the situationally conditioned task scheme of its objects study. Due to the lack of experience they immediately, unprepared, switched over to search actions within the task space limits, creating solutions in the process of moving forward within the task situation. It is reflected in the typical ranking of mental acts: operative (evaluation and implementation) $(0,423)$; planning $(0,342)$, preparatory $(0,102)$. Politicians used relevant information from their experience while students used alternative knowledge about the object which mostly had drawbacks since they were partially irrelevant as to the subject matter of the task to be solved. It is interesting that the prevailing motive of the students «taking the power» (just like in the case with the politicians); the motive «to know» 
$(0,345)$ is uniformly distributed in all tasks which testifies to the practicality of their thinking.

Interesting is the indicator of «knowledge transfer», since actors strived to transfer the experience from civil, social, study, trade-union and other types of activity into political practice. And since it has its own specifics, such experience without due correction was not productive and led to wrong orientation in the task.

Brightly expressed motivation of the orientation towards the «reference», the ideal can be explained by the peculiarities of value and motivational formation of an individual in adolescent age, interrelation of "real I" and "ideal I" etc. «Orientation towards own self» $(0,247)$ and orientation «towards others» $(0,426)$ testifies to the participation in the political events «for the sake of everyone», «for the sake of what we are doing», «normal life in the country», «to chase away the corruptionists», «to reload the power» etc. No conscious orientation towards originality has been revealed, however originality as a mechanism of political activity has remained. It was manifested in strategic tendencies of random substitutions, analogization in the process of solving of sub-tasks : «How can I find a possibility to be present on Maidan and continue with the study process?», «What should I say about my participation on Maidan and what should I keep secret?» etc. Here is a fragment of the conversation record of the experimenter (E) and a student $(S)$ in the process of solving of a decision-making task:

S. I will go to express my disagreement with the president's policy (DM task).

E. In what form to express?

S. Well, I will sing the anthem, help others (hypothesis).

E. Imagine that you have already expressed your disagreement, what happens next?

S. I will go to get rid of the old power (task reformulation).

E. What resources do you have?

S. /pause/ ... time, health, wish (singling out the components)

E. What about money? What other resources are needed?

S. /pausel

E. Do you think it is enough?

S. Probably ... no, but there are a lot of us ... (hypothesis)

E. What will you do with the new power?

s. /pausel

E. What do you need the new power for?

S. A new, dignified president must be elected (task reformulation).

E. Dignified - please explain

S. /pausel

E. What qualities must he have?

$\mathrm{S}$. Well, ... a respectable person, a good specialist ... (singling out of the element features)

E. That's it? And what will you do?

$\mathrm{S}$. When? (specification)

E. When you will have such a president

S. /pausel

E. Will there be any changes in your life?

S. Yes, I won't feel ashamed for my country (hypothesis).

The search process was accompanied by emotional straining $(0,794)$. Actors single out politics as a subject as intensely as possible in significant tasks. Thus all four task types uniformly yielded to reformulation $(0,201)$. The correlation of the presence of hypotheses $(0,344)$, theoretical generalizations $(0,566)$, preliminary conclusions $(0,223)$, which concerned the possibilities to solve the task, testifies to diffusedness, poor structuredness of the search process and illogical political thinking (here we agree with D.Olshanskiy). The absence of any specific preliminary experience and sufficient knowledge of the subject were manifested in A, DM tasks $(0,134)$ and the total absence of procedural knowledge preconditioned the situation when generalizations took place according to a random characteristic of the task situation. Typical is moderately expressed independence $(0,342)$, confidence about tasks solving $(0,364)$, and in significant tasks even assertiveness $(0,643)$, perseverance $(0,856)$; intellectual initiative appeared homogeneous - when all tasks were solved with the same intensity $(0,341)$.

The stage of task specification $(0,225)$, formulation of the necessary conditions, was followed by the hypotheses sub-stage only in A, DM tasks. In fact solving of other tasks discontinued. Maximally expressed «knowledge about the lack of knowledge» $(0,856)$ might be related to the clear attitude that "they understand nothing in politics», «... it is not possible to understand anything because everyone is a politician ...». At the same time «knowledge about knowledge» is expressed moderately and uniformly in all tasks $(0,231)$. 
Typical is adherence to ideal norms $(0,541)$ and standard norms $(0,795)$. Although in our opinion these are rather social stereotypes of social and political ideal norms actors are oriented towards when solving tasks. Orientation towards meanings $(0,645)$, or rather singling out of attractive meanings and the meanings which are a negative sign as to different position in a situation are most essential $(0,342)$, which testifies either to populism or to the actor trying to obtain immediate effect "here and now" without really understanding further perspectives for his activity.

Typical are the following tactics: orientation towards meanings $(0,465)$; exaggerations $(0,341)$; orientation towards functionality $(0,184)$; structural and functional transformations $(0,237)$; reduction etc. They functioned in strategic tendencies of political thinking which had the following hierarchy of actions: analogizing, random substitutions, reconstruction, recombination.

\section{Conclusions}

Strategic organization of actor's political thinking has been revealed, which is a system of mental acts directed towards task solving. Thinking strategy has the following stages: studying of the task specifications; development of a preliminary solving suggestion; verification of the specifications with the help of a concrete knowledge (theoretical and practical); choosing of a hypothesis as to structural and functional transformation of the task components; "projecting» of the hypothesis on the task specifications in general and its specific usage; hypothesis verification; detailed elaboration and consideration of general contexts and specific «field» conditions. Typology of the political thinking style is preconditioned by the type of intellectual political activity and the type of task as its model. So, political thinking is of three types professional (typical of actual politicians), potentially professional (typical of future specialists in the sphere of politics) and everyday (unprofessional, pertaining to an ordinary actori) - which it would be useful to consider in the domestic political practice.

\section{References}

Ball, G.A. (1990). The theory of learning tasks: Psycho-pedagogical aspect. Pedagogika. 184 p.

Bruner, G. (1977). The psycology of the cognition. Beyond the immediate information; transl. from eng K.I. Babickiy. Progress.

Zavalishina, D.N. (2005). The practical thinking: Specificity and Problems of Development. "Institute of Psychology RAS ".376 p.

Kozeleckiy, Yu. (1979). Psychological decision theory; transl. from pol G.E. Mints, V.N. Porus / edited by B.V. Biryukova. Progress. 504

p.

Levenets, Yu.A. (2011). Politics / Political encyclopedia. Parliamentary publisher. P. 567-568.

Lomov, B. (1984). Methodological and Dynamic Problems of psychology. Nayka. 444 p.

Molyako, V.A. (2007). The creative Constructilogy (prolegomenon). "Osvita Ukrainy". P. 101.

Ol'shanskiy, D.V. (2001). Foundations of Political Psychology. Delovaya kniga, Ekaterinburg.

Tolochek, B.V. (1998). Styles professional activities as part of the problem of identity in psychology / Vladimir Tolochek / The human style: psychological analysis / edited by A. V. Libina. $310 \mathrm{p}$.

Traverse, T.M. (2014). System-strategic and political thinking concept (continued) // Theoretical and applied problems of psychology: Collected Works of East Ukrainian National University Volodymyr Dahl. Publication «NOULIDZh». № 2(34). 406 p. 